\title{
EXEQUIBILIDADE DA PENHORA DE CRIPTOMOEDAS NO PROCESSO DE EXECUÇÃO BRASILEIRO
}

\author{
Alexandre Ferreira de Assumpção Alves ${ }^{1}$ \\ Priscilla Menezes da Silva ${ }^{2}$
}

\section{RESUMO}

O trabalho investiga a possibilidade de penhora das moedas virtuais. Os objetivos específicos são: (i) descrever a evolução da moeda para compreender o surgimento das criptomoedas, suas características e funcionamento; (ii) analisar a natureza jurídica das moedas virtuais para verificar a possibilidade de atos de constrição judicial; (iii) apresentar argumentos para refutar a premissa que a falta de controle pelo Banco Central torna inócuas as determinações judiciais; (iv) criticar a decisão da Trigésima Sexta Câmara de Direito Privado do TJSP, leading case sobre o tema. $\mathrm{O}$ método de pesquisa é o dedutivo, baseado em pesquisas bibliográfica, legislativa e jurisprudencial.

Palavras-chaves: Criptomoedas; Penhora; Moeda Digital; Bicoin; Processo de Execução

\section{FEASIBILITY OF CRYPTOCURRENCIES SEIZURE IN THE BRAZILIAN EXECUTION PROCESS}

\begin{abstract}
This paper investigate the possibility of cryptocurrencies seisure. Its specific goals are: (i) description of the evolution of the concept of currency to understand the emergence of digital currencies, its characteristics and how they work; (ii) analysis of the legal nature of cryptocurrencies to verify the possibility of seizure; (iii) to refute the premise that the absence of control from the Central Bank makes court orders useless; (iv) criticise the decision from the Thirty Sixth Chamber of State Court of São Paulo, the Brazilian leading case. The research method applied is the deductive, based on bibliographic, legislative and jurisprudential research.
\end{abstract}

Keywords: Cryptocurrency; Seizure; Digital Currency; Bitcoin; Execution Process

\section{INTRODUÇÃO}

Os tempos mudaram e a revolução tecnológica tem interferido na forma de se relacionar e trabalhar, tendo inclusive reflexos patrimoniais. Diante de tantas tecnologias disruptivas, está em voga em vários países a discussão sobre a adequação da legislação vigente a este mundo novo em rápido desenvolvimento. É claro que na maioria dos casos

\footnotetext{
${ }^{1}$ Mestre e Doutor em Direito (UERJ). Professor Associado do PPGD da UERJ. Professor Associado da FND/UFRJ. Expositor na Escola da Magistratura do Estado do Rio de Janeiro - EMERJ

${ }^{2}$ Doutoranda em Direito pela UERJ. Mestre em Direito da Empresa e Atividades Econômicas pela UERJ. Especialista em Direito Empresarial pela Universidade Cândido Mendes. Expositora na EMERJ. Advogada.
} 
primeiro surgem os fatos sociais, depois o direito regula-los. Nem sempre as situações concretas são subsumidas com exatidão nas normas existentes, o que demanda dos operadores do direito exercícios hermenêuticos e análise sistêmica para resolver tais situações.

Desde 2013 tem se assistido a um crescimento exponencial das criptomoedas, também conhecidas como moedas virtuais, sendo a mais conhecida o Bitcoin. Estas moedas, por conta de características que serão explicitadas ao longo deste trabalho, são usadas para as mais diversas finalidades: investimento, transações comerciais, operações criminosas como tráfico de armas. Porém, a partir do final de 2017, as criptomoedas também começaram a aparecer como tema de debates em processos de execução e questões familiares relacionadas à partilha de bens, o que justifica a relevância e atualidade do tema.

Neste contexto, o presente artigo tem como objetivo geral avaliar a viabilidade jurídica e a eficácia de penhora de criptomoedas segundo as normas do Código de Processo Civil.

A fim de responder tal indagação, será necessário desenvolver os seguintes objetivos específicos: (i) descrever a evolução da moeda a fim de compreender o contexto que viabilizou o surgimento das criptomoedas, suas características e como funcionam; (ii) analisar a natureza jurídica das moedas virtuais a fim de definir, em um primeiro momento, se são passíveis de atos de constrição judicial; (iii) apresentar argumentos que refutem a premissa de que a ausência de controle por parte do Banco Cental do Brasil torna inócuas as determinações judiciais; (iv) questionar a decisão da Trigésima Sexta Câmara de Direito Privado do Tribunal de Justiça de São Paulo, proferida em dezembro de 2017que constituiu o leading case sobre o tema.

Para desenvolver esta proposta a contento, será utilizado como método de pesquisa o dedutivo, partindo de uma abordagem geral sobre as criptomoedas e suas funções, para então contrastá-la com o primeiro caso julgado em segunda instância de que se tem notícia no Brasil. Serão implementadas pesquisas bibliográfica e legislativa, bem como jurisprudencial.

Este trabalho será desenvolvido em três partes: primeiramente, a compreensão do que são criptomoedas, como surgem, suas características e rápida expansão; em um segundo momento analisar-se-ão alguns dispositivos do Código de Processo Civil a fim de verificar se são suficientes e adequados para viabilizar a penhora e alienação de moedas virtuais em processos de execução e, por fim, proceder-se-á à análise crítica da primeira decisão sobre o assunto proferida por um tribunal brasileiro.

\section{O QUE SÃO CRIPTOMOEDAS?}


A fim de compreender a exequibilidade da penhora de criptomoedas e seus fundamentos, faz-se mister de antemão explanar o que são as criptomoedas e suas características. Deve-se perceber como se chegou ao ambiente ideal para sua concepção e desenvolvimento dos meios de pagamento. Para tanto, far-se-á uma breve digressão histórica sobre o surgimento e evolução da moeda para então analisar especificamente o Bitcoin, a moeda virtual mais conhecida nos dias atuais.

\subsection{Uma breve digressão histórica da moeda}

A moeda como é conhecida nos dias atuais advém de um longo e profundo processo de desenvolvimento das relações humanas. A fim de realizar uma rápida digressão histórica sobre ela, identificam-se sete estágios de desenvolvimento: (i) mercadoria-moeda; (ii) moedas de metal; (iii) papel-moeda; (iv) cheque; (v) cartão de crédito; (vi) transações pela internet e (vii) criptomoedas. A fim de compreender o atual estágio socioeconômico que viabilizou o surgimento e aumento das transações com criptomoedas, analisar-se-á brevemente a arqueologia da moeda.

Nos primórdios da civilização, quem conseguisse obter excedentes de alguma coisa podia trocá-la por algo que precisasse. Peixes, grãos, manufaturas, tudo podia ser objeto de permuta. Tal prática ficou conhecida como escambo, no qual se buscava trocar bens de valor equivalente.

Com o desenvolvimento das relações e atividades comerciais, alguns itens que tinham maior procura assumiram a função de moeda ${ }^{3}$. No Brasil, muitas mercadorias ${ }^{4}$ já desempenharam este papel: gado, pau-brasil, açúcar, cacau e tabaco são alguns exemplos (GUIA MUNDO, 2018, p. 12). Porém, devido à oscilação de seu valor, dificuldade de deslocamento e perecimento de determinados itens, as mercadorias se tornaram inconvenientes para as transações comerciais e foram substituídas por metais.

\footnotetext{
${ }^{3}$ Aqui não se refere à moeda como objeto circular de metal, emitido por instituição governamental, mas sim como um meio que viabiliza transações de valores.

${ }^{4}$ Esse período histórico deixou marcas na cultura e idioma brasileiros. O gado e o sal (que outrora serviram de moeda de troca) aparecem no vocabulário do brasileiro de variadas formas: a palavra latina pecus (gado) deu origem à pecúnia (dinheiro) e pecúlio (dinheiro acumulado); o sal, que já foi usado como meio de pagamento por serviços prestados, deu origem à palavra salário. Cf. BRASIL. BANCO CENTRAL DO BRASIL. Museu de Valores do Banco Central. Disponível em: 〈https://www.bcb.gov.br/htms/origevol.asp>. Acesso em: 19.mar.2018.
} 
Quando o homem descobriu os metais passou a utilizá-los para produzir utensílios que eram esculpidos em pedra anteriormente. Esses objetos de metal passaram então a ser utilizados como moeda de troca, o que tornava as transações morosas devido à necessidade de aferição de peso, por exemplo.

No século VI a.C. surgiram as primeiras moedas parecidas com as de hoje. Com a padronização que se seguiu, as moedas de metal passaram a ter peso e forma pré definidos. $\mathrm{O}$ valor era derivado do cunho oficial, aposto por quem produziu a moeda e garantia o seu valor. Grécia e Lídia (atual Turquia) foram os primeiros a ter moedas neste formato. ${ }^{5}$

As moedas metálicas foram utilizadas por muitos séculos, primeiro em ouro e prata e depois em cobre. Durante a Idade Média surgiu o costume de guardar grande volumes de valores em metais preciosos com ourives. Este, por sua vez, como garantia entregava um recibo que passou a ser utilizado como meio de pagamento, passando de mão em mão, ou seja, circulando entre as pessoas, no mercado. Assim, o recibo do ourives evoluiu até surgir o papel moeda. Com o tempo, os governos passaram a conduzir as emissões, controlando a qualidade e aprimorando técnicas para coibir falsificações.

Embora haja relatos de que no ano de 960 a.C. chineses já usavam papel moeda em forma muito parecida com a que se tem hoje, ele caiu em desuso e só reapareceu na Suécia em 1661 (MARKET PLACE, 2017). Fato curioso é que o país que "criou" o papel-moeda promete acabar com ele até 2023. A Suécia lidera os índices de transações digitais no mundo (FORTUNE, 2015). As moedas cunhadas em metais apresentavam diversas vantagens: não eram perecíveis, seu transporte era fácil, sua raridade ajudava a manter seu valor elevado, facilitavam o acúmulo de riqueza e recolhimento de impostos pelos governos.

O conjunto de cédulas e moedas de cada país forma seu sistema monetário. Esse sistema é regulado por legislação específica e tem autoridades governamentais encarregadas de seu controle. Quase todos os países tem seus respectivos Bancos Centrais e Casas da Moeda para, respectivamente, controle de política monetárias e emissão de dinheiro.

A moeda bancária, também chamada de escritural, é movimentada através de cheques. Baseado em um contrato de abertura de conta corrente, o cliente de qualquer banco ou outra instituição equiparada pode emitir ordem de pagamento contra o sacado (banco) à vista dos depósitos que este detém em nome do cliente ou de crédito que tenha sido colocado à sua

BRASIL. BANCO CENTRAL DO BRASIL. Op. cit. Disponível em: <https://www.bcb.gov.br/htms/origevol.asp>. Acesso em: 19 mar. 2018. 
disposição. ${ }^{6}$ Embora estejam caindo em desuso, os cheques ainda são emitidos como meio de pagamento e, principalmente no ramo imobiliário, os cheques administrativos ${ }^{7}$ são prática muito comum.

Cada vez mais, moedas e cédulas vem sendo substituídas por cartões de crédito emitidos por instituições financeiras e por algumas lojas (cartões private label). Entretanto, a origem desses cartões como se conhece hoje não está no setor bancário, como se poderia imaginar.

Celso Marcelo de Oliveira (2003, p. 6) explica a origem do cartão de crédito.

O primeiro cartão de crédito deste tipo atual foi o Diners Club, surgido em 1949 [nos Estados Unidos]. O presidente desta cadeia de restaurantes, Robert Macnamara, num jantar de amigos, constatou que havia se esquecido do talão de cheques. Não vencido pelo constrangimento, imaginou a criação de um documento que comprovasse a identidade do seu portador e lhe conferisse crédito.

Gerou-se assim este cartão que permitia a cerca de 200 membros a utilização de restaurantes de Nova Iorque sem a necessidade de realizar o pagamento imediato. Inicialmente restrito a uma rede de hoteis e restaurantes afiliados, o leque de opções logo se estendeu a diversos tipos de empresas. Em 1958, a American Express, originalmente uma agência de viagens, também criou um cartão semelhante e, no ano seguinte, o cartão Visa, indubitavelmente os mais famosos cartões de crédito do mundo.

Embora não seja dinheiro e represente somente uma intenção de pagamento por parte do titular, o risco de não pagamento não fica mais com o então comerciante, hoje empresário, que mediante o pagamento de uma taxa incidente sobre cada transação recebe o valor referente às suas vendas. É a emissora do cartão quem assume os riscos de eventual inadimplência do titular. Tal fato, principalmente a partir da década de 1960, serviu de mola propulsora da economia da época. Os cartões de crédito, a partir de então predominantemente bancários, passaram a servir como importante instrumento de concessão e estímulo ao crédito (MARTINS, 1976, p.23). ${ }^{8}$

\footnotetext{
${ }^{6}$ Art. $4^{\circ}$ da Lei n. $7.357 / 85$.

${ }^{7}$ O Cheque administrativo, além de espécie de cheque reconhecida desde o Decreto no $24.777 / 34$, é um serviço oferecido pelas instituições financeiras aos seus clientes. Mediante pagamento de uma taxa (geralmente R\$ $30,00)$ o banco desconta da conta do cliente uma quantia determinada e lhe entrega um cheque administrativo no mesmo valor. Tal cheque é sacado contra o próprio banco sacador e não pode ser ao portador (art. $9^{\circ}$, III, da Lei $\mathrm{n}^{\mathrm{o}} 7.357 / 85$ ).

${ }^{8}$ Sobre o efeito maléfico da concessão indiscriminada de crédito via cartões de crédito e outros produtos bancários e não bancários vide o artigo Superendividamento e seus efeitos sociais e econômicos para o consumidor e o empresário: a necessidade premente de uma tutela jurídica específica para o problema, disponível em: <http://www.publicadireito.com.br/artigos/?cod=feafb280b99f47d2>.
} 
A expansão da internet comercial e doméstica na década de 1990, aumentou significativamente as transações online entre consumidores e empresários (modelo B2C) e entre empresários (modelo B2B). ${ }^{9}$ Com o advento da Quarta Revolução Industrial, baseada na revolução digital, "caracterizada por uma internet mais ubíqua e móvel” (SCHWAB, 2016, p.16) foi viabilizado o surgimento e expansão do que se convencionou chamar de criptomoedas.

\subsection{Surgimento, características e expansão das criptomoedas}

Antes de explicar o que são as criptomoedas, também chamadas de moedas virtuais, é preciso diferenciá-las das moedas eletrônicas. Estas são representadas pelos recursos em reais armazenados em dispositivo ou sistema eletrônico que permitem ao usuário final efetuar transação de pagamento. Quando se paga uma conta ou se faz uma transferência através do internet banking movimenta-se moeda eletrônica, regulada pela Lei no $12.865 / 2013^{10}$.

A moeda eletrônica é representada em reais. A transferência de $\mathrm{R} \$ 100,00$ (cem reais) por dispositivos online equivale rigorosamente a $\mathrm{R} \$ 100,00$. Com as criptomoedas não funciona assim. Dentre todas as moedas virtuais existentes hoje, a mais conhecida pela população em geral é o Bitcoin. Por questões de eficiência didática opta-se por tratar aqui de seu surgimento, características (que são as mesmas para as criptomoedas em geral) e expansão.

Em 2008, uma pessoa (ou um grupo de pessoas, não se sabe ao certo) sob a alcunha de Satoshi Nakamoto divulgou um artigo em inglês no qual detalhava o conceito do Bitcoin. A proposta consistia em operações financeiras ponto a ponto (peer to peer) sem intermediação,

\footnotetext{
${ }^{9}$ No jargão econômico, operações B2C são Business to Commerce e B2B são Business to Business.

${ }^{10}$ A moeda eletrônica integra o Sistema de Pagamentos Brasileiro (SPB) e é conceituada pelo art. $6^{\circ}$, VI, da Lei $n^{\circ}$ 12.865/2013 como "VI - moeda eletrônica - recursos armazenados em dispositivo ou sistema eletrônico que permitem ao usuário final efetuar transação de pagamento." A conversão de moeda física ou escritural em moeda eletrônica é uma atividade privativa de "instituição de pagamento", definida no art. $6^{\circ}$, III, como a "pessoa jurídica que, aderindo a um ou mais arranjos de pagamento, tenha como atividade principal ou acessória, alternativa ou cumulativamente: a) disponibilizar serviço de aporte ou saque de recursos mantidos em conta de pagamento; b) executar ou facilitar a instrução de pagamento relacionada a determinado serviço de pagamento, inclusive transferência originada de ou destinada a conta de pagamento; c) gerir conta de pagamento; d) emitir instrumento de pagamento; e) credenciar a aceitação de instrumento de pagamento; f) executar remessa de fundos; g) converter moeda física ou escritural em moeda eletrônica, ou vice-versa, credenciar a aceitação ou gerir o uso de moeda eletrônica; e h) outras atividades relacionadas à prestação de serviço de pagamento, designadas pelo Banco Central do Brasil. É da competência do Banco Central do Brasil, conforme diretrizes estabelecidas pelo Conselho Monetário Nacional, na forma do art. $9^{\circ}$, II, da Lei $\mathrm{n}^{\circ}$ 12.865/2013 disciplinar a constituição, o funcionamento e a fiscalização das instituições de pagamento, bem como a descontinuidade na prestação de seus serviços.
} 
ou seja, sem instituições financeiras e, portanto sem taxas (NAKAMOTO: [s/d]). Além do custo zero, outra característica vantajosa oferecida era a preservação da privacidade, pois todas as transações são criptografadas. As operações são validadas por um protocolo chamado Blockchain, que funciona como um livro-razão virtual (TAPSCOTT; TAPSCOTT, 2016, p. 193), descentralizado, logo impossível de ser hackeado. Não há uma autoridade central nem para controle nem para emissão de Bitcoins. ${ }^{11}$

Em 2009, o primeiro lote de Bitcoins foi minerado (genesis block) e, em 2010, houve a primeira transação: a compra de uma pizza nos EUA. Pelo seu inegável caráter político, no período de 2011 a 2012 esta moeda virtual foi usada para financiar o site Wikileaks, que tem por objetivo principal divulgar documentos sigilosos de vários Governos, principalmente dos EUA. Contudo, a grande notoriedade e expansão da moeda ocorreu em 2013, quando o Governo de Chipre, por conta de grave crise econômica, dava sinais de que confisco de poupanças e investimentos era iminente, milhares de cidadãos utilizaram o Bitcoin como forma de proteção de divisas. O confisco não aconteceu.

A partir de então, as transações com Bitcoins começaram a aumentar, principalmente por conta de duas vantagens em relação ao sistema financeiro tradicional. Cite-se, por exemplo, a realização de remessas de dinheiro para o exterior. A tabela abaixo revela a praticidade, economicidade e celeridade em relação às remessas realizadas por criptomoedas.

\section{Tabela I - Formas de fazer remessa para o exterior}

\begin{tabular}{|c|c|c|c|}
\hline Meio & Valor & Taxa & Tempo médio \\
\hline Banco Santander & $\mathrm{R} \$ 1.000,00$ & $\mathrm{R} \$ 90,00$ & Até $48 \mathrm{~h}$ \\
\hline Western Union & $\mathrm{R} \$ 1.000,00$ & $\mathrm{R} \$ 50,00$ & Até $24 \mathrm{~h}$ \\
\hline Criptomoedas & $\mathrm{R} \$ 1.000,00$ & - & Até 10 minutos \\
\hline
\end{tabular}

Fonte: Elaboração própria.

\footnotetext{
${ }^{11}$ Há basicamente três formas de se adquirir Bitcoins: (i) através da atividade de mineração. Super computadores decifram problemas matemáticos presentes na programação criada por Satoshi Nakamoto e o "prêmio" é um bloco de Bitcoin. O sistema foi programado para emitir no máximo 21 milhões de Bitcoins (outras criptomoedas como Ethereum não tem esse limite). Até janeiro de 2018, 80\% dos Bitcoins já haviam sido minerados; a segunda forma de adquirir Bitcoins é através de corretoras ou casas de câmbio; a terceira forma é prestar um serviço ou vender mercadorias e aceitar Bitcoins como forma de pagamento.
} 
Percebe-se pela tabela acima que as transações financeiras com criptomoedas oferecem economicidade ${ }^{12}$ e celeridade quando comparadas com outras formas de operações financeiras, justamente por terem eliminado a presença do intermediário, já que as operações baseadas em Blockchain são ponto a ponto (peer to peer). A burocracia e exigência de documentos também é menor quando se trata de moedas virtuais, porque toda a verificação de documentos ocorre apenas quando se cria uma carteira digital (virtual wallet). Alguns bancos, por questões de adesão a programas de integridade ou conformidade (compliance), exigem preenchimento de formulários a cada transação e justificativa para as remessas (ex. envio de dinheiro para parentes, contratos de prestação de serviços, etc).

Todas as características que representam vantagens nas transações com criptomoedas (manutenção da privacidade através de criptografia, economicidade, praticidade e celeridade) vêm acompanhadas de uma feição delicada. Por não serem as criptomoedas sujeitas ao controle de nenhum governo (não se estende às criptomoedas o controle do Banco Central do Brasil sobre a moeda eletrônica), e não terem leis específicas, ${ }^{13}$ têm seu valor definido com base na confiança dos peers e na sua demanda. Há uma imensa volatilidade, consoante tabela a seguir.

\section{Tabela II - Oscilações nos valores das principais criptomoedas em um dia (24/03/2018)}

\footnotetext{
${ }^{12}$ Nas operações com intermediários há ainda a cobrança do imposto sobre operações financeiras (IOF), atualmente na alíquota de $1,10 \%$ sobre o valor da transação.

${ }^{13} \mathrm{Em}$ muitos países se discute qual seria a melhor forma de regulamentar as criptomoedas. No Brasil, o Projeto de Lei ${ }^{\circ}$ 2.303/2015 propõe regulá-las como meio de pagamento. O referido PL, apresentado na Câmara dos Deputados em 08/07/2015 pelo Deputado Áureo (RJ) e em tramitação, dispõe sobre a inclusão das moedas virtuais e programas de milhagem aéreas na definição de "arranjos de pagamento" sob a supervisão do Banco Central, alterando as Leis ${ }^{\circ}$ 12.865/2013 e 9.613/1988 (Lei de Lavagem de Dinheiro) e determinando que se aplicam às operações conduzidas no mercado virtual de moedas, no que couber, as disposições do Código de Defesa do Consumidor. Caso o projeto seja aprovado e a lei promulgada, será alterada a redação do inciso I, do art. $9^{\circ}$, da Lei 12.865/ 2013 e incluído um parágrafo no art. 11 da Lei no 9.613/1988. Em 13/12/2017, Comissão Especial aprovou o Parecer do Relator, Dep. Expedito Netto (RO), pela constitucionalidade, juridicidade e técnica legislativa; pela não implicação da matéria em aumento ou diminuição da receita ou da despesa públicas, não cabendo pronunciamento quanto à adequação financeira e orçamentária; e, no mérito, pela aprovação, com substitutivo.
} 


\begin{tabular}{|c|c|c|c|c|c|c|c|c|c|}
\hline \multirow{2}{*}{$\begin{array}{l}\text { All v } \\
\qquad \#\end{array}$} & \multicolumn{2}{|c|}{ Coins - Tokens } & \multicolumn{2}{|c|}{ USD. } & \multirow[b]{2}{*}{ Circulating Supply } & \multirow[b]{2}{*}{ Volume (24h) } & \multirow[b]{2}{*}{$\% 1 \mathrm{~h}$} & \multicolumn{2}{|c|}{$\leftarrow$ Back to Top 100} \\
\hline & Name & Symbol & Market Cap & Price & & & & $\% 24 h$ & $\% 7 d$ \\
\hline 1 & (3) Bitcoin & BTC & $\$ 143,906,231,446$ & $\$ 8,497.67$ & $16,934,787$ & $\$ 5,244,660,000$ & $-0.12 \%$ & $-2.99 \%$ & $2.11 \%$ \\
\hline 2 & Ethereum & ETH & $\$ 51,146,585,149$ & $\$ 519.97$ & $98,364,114$ & $\$ 1,544,870,000$ & $-0.39 \%$ & $-4.34 \%$ & $-14.76 \%$ \\
\hline 3 & of Ripple & XRP & $\$ 24,842,856,774$ & $\$ 0.635461$ & $39,094,227,299$ * & $\$ 423,296,000$ & $0.10 \%$ & $-4.30 \%$ & $-8.73 \%$ \\
\hline 4 & [0] Bitcoin Cash & $\mathrm{BCH}$ & $\$ 16,809,652,771$ & $\$ 986.87$ & $17,033,300$ & $\$ 334,345,000$ & $0.31 \%$ & $-2.53 \%$ & $4.35 \%$ \\
\hline 5 & Litecoin & LTC & $\$ 8,928,710,922$ & $\$ 160.14$ & $55,754,264$ & $\$ 383,408,000$ & $0.42 \%$ & $-3.59 \%$ & $-2.25 \%$ \\
\hline
\end{tabular}

Fonte: Coin News Telegraph

Embora a volatilidade das criptomoedas seja imensa e torne difícil a sua valoração em termos patrimoniais (uma pessoa que tem $\mathrm{R} \$ 700$ mil em Bitcoins hoje pode ter apenas $\mathrm{R} \$$ 300 mil amanhã), e ainda haja muita incerteza acerca de sua verdadeira natureza jurídica, ${ }^{14}$ fato incontroverso é que são bens imateriais dotados de valor econômico, portanto, em tese, passíveis de sofrerem atos de constrição patrimonial pela via judicial. É o que se examina a seguir.

\section{ADEQUAÇÃo do Código de PROCESSO CIVIL BRASILEIRO À NOVA REALIDADE ECONÔMICA EM DESENVOLVIMENTO}

Desde 2013 milhares de pessoas ao redor do mundo começaram a fazer operações com criptomoedas, com as mais diversas finalidades: há os que acreditam no caráter políticolibertário de uma transação fora da regulação e fiscalização do Estado; há os que desejam especular e ganhar com a alta volatilidade dessas moedas. Infelizmente existem pessoas que

\footnotetext{
${ }^{14}$ Embora o Banco Central do Brasil e a Comissão de Valores Mobiliários ainda não tenham alcançado uma definição exata para enquadrar estes "bens" ou "valores" em categorias já existente e definir a quem caberia a regulação, a Receita Federal, para fins de tributação, definiu que as criptomoedas estão sujeitas à incidência de imposto de renda (alíquota de 15\%) quando houver ganho de capital. Valores superiores a $R \$ 1.000,00$ (hum mil reais) em criptomoedas já precisam ser declarados, mas a tributação só ocorre quando se o valor ultrapassar R \$ 35.000,00 (trinta e cinco mil reais). No Manual de Perguntas e Repostas do IR 2018 (http://idg.receita.fazenda.gov.br/interface/cidadao/irpf/2018/perguntao/perguntas-e-respostas-irpf-2018-v-1-

$\underline{0 . p d f}$, p. 182), a pergunta 447 indaga se as moedas virtuais devem ser declaradas. A resposta do Fisco é "Sim. As moedas virtuais (bitcoins, por exemplo), muito embora não sejam consideradas como moeda nos termos do marco regulatório atual, devem ser declaradas na Ficha Bens e Direitos como "outros bens", uma vez que podem ser equiparadas a um ativo financeiro. Elas devem ser declaradas pelo valor de aquisição. [...] Como esse tipo de "moeda" não possui cotação oficial, uma vez que não há um órgão responsável pelo controle de sua emissão, não há uma regra legal de conversão dos valores para fins tributários. Entretanto, essas operações deverão estar comprovadas com documentação hábil e idônea para fins de tributação."
} 
se aproveitam do anonimato para praticar atos ilícitos como transações oriundas de tráfico de drogas, lavagem de dinheiro; e há ainda aqueles que buscam ocultar patrimônio de credores e ex-cônjuges.

Neste cenário, após a compreensão acerca do que são e como funcionam as criptomoedas, é importante verificar se elas podem ser penhoradas e e eficácia de uma ordem judicial nesse sentido.

\subsection{Exequibilidade de criptomoedas no processo civil brasileiro e sua eficácia}

Segundo o art. 789 do Código de Processo Civil (CPC), o devedor, pessoa física ou jurídica, responde com todos os seus bens, presentes e futuros, pelas suas obrigações. Sendo assim, pelo princípio da responsabilidade patrimonial, como as criptomoedas são bens imateriais com conteúdo econômico, fazem parte do patrimônio de devedor.

Ultrapassada esta primeira premissa, é necessário analisar se esta categoria de bens incorpóreos pode ser objeto de constrição judicial, ou seja, se podem ser penhoradas. $\mathrm{O}$ art. 833 do CPC traz um rol taxativo de bens impenhoráveis, conforme segue:

Art. 833. São impenhoráveis:

I - os bens inalienáveis e os declarados, por ato voluntário, não sujeitos à execução;

II - os móveis, os pertences e as utilidades domésticas que guarnecem a residência do executado, salvo os de elevado valor ou os que ultrapassem as necessidades comuns correspondentes a um médio padrão de vida;

III - os vestuários, bem como os pertences de uso pessoal do executado, salvo se de elevado valor;

IV - os vencimentos, os subsídios, os soldos, os salários, as remunerações, os proventos de aposentadoria, as pensões, os pecúlios e os montepios, bem como as quantias recebidas por liberalidade de terceiro e destinadas ao sustento do devedor e de sua família, os ganhos de trabalhador autônomo e os honorários de profissional liberal, ressalvado o $§ 2^{\circ}$;

V - os livros, as máquinas, as ferramentas, os utensílios, os instrumentos ou outros bens móveis necessários ou úteis ao exercício da profissão do executado;

VI - o seguro de vida;

VII - os materiais necessários para obras em andamento, salvo se essas forem penhoradas; 
VIII - a pequena propriedade rural, assim definida em lei, desde que trabalhada pela família;

IX - os recursos públicos recebidos por instituições privadas para aplicação compulsória em educação, saúde ou assistência social;

X - a quantia depositada em caderneta de poupança, até o limite de 40 (quarenta) salários-mínimos;

XI - os recursos públicos do fundo partidário recebidos por partido político, nos termos da lei;

XII - os créditos oriundos de alienação de unidades imobiliárias, sob regime de incorporação imobiliária, vinculados à execução da obra.

Sendo a penhorabilidade a regra e a impenhorabilidade a exceção, razão pela qual deve ser interpretada restritivamente, não se encontra amparo na legislação em vigor para excluir as criptomoedas da possibilidade de penhora.

Superado este ponto, poder-se-ia argumentar que a elevadíssima volatilidade desses bens tornaria uma medida de constrição inócua, na medida em que no momento da penhora a avaliação apontaria um valor e no momento da expropriação para satisfação do débito o valor fatalmente seria outro. A liquidez da obrigação exequenda e a necessidade de garantir a execução com a penhora seriam duramente afetadas.

Em parte o argumento supra é verdadeiro, pois devido ao tempo de duração dos processos judiciais, em regra morosos, há um lapso relativamente longo entre o ato da penhora e a efetiva expropriação. Sem embargo, este não é um problema que aflige exclusivamente as criptomoedas. A penhora de bens com cotação em bolsa (commodities), por exemplo, oferece a mesma dificuldade há muito tempo, como se verifica no julgado abaixo do Tribunal Regional Federal da Terceira Região, com jurisdição sobre os Estados de São Paulo e Mato Grosso do Sul (BRASIL. Tribunal Regional Federal. Terceira Região: 2007).

PROCESSUAL CIVIL - AGRAVO DE INSTRUMENTO - EXECUÇÃO FISCAL - HASTA PÚBLICA - SACAS DE AÇÚCAR ARREMATAÇÃO - DEPÓSITO DA PRIMEIRA PARCELA PELO ARREMATANTE - INEXISTÊNCIA DO BEM PARA REMOÇÃO ANULAÇÃO DO AUTO DE ARREMATAÇÃO - DEPÓSITO DO VALOR DO BEM ARREMATADO - VALOR ATUALIZADO COTAÇÃO DO BEM - ÍNDICE CEPEA/ESALQ - AGRAVO PARCIALMENTE PROVIDO. 
1 - Como o açúcar tem cotação no mercado, desnecessária a remessa dos autos à Contadoria Judicial para apuração da equivalência entre o já depositado e o débito cobrado na execução fiscal.

2 - A execução fiscal não visa à satisfação do arrematante, mas do credor, até o valor do débito exequendo, que atualizado para o edital de leilão (6/12/2005) no montante de R $\$ 139.936,88$.

3 - Ademais, porque o arrematante não teve prejuízo, pois o valor da arrematação (R\$ 140.000,00) foi integralmente depositado, corrigido, totalizando R\$163.763,23.

4 - O valor que pretende a União, ou seja, $\mathrm{R} \$ 259.074,39$, corresponde não ao prejuízo do arrematante, mas ao que ele deixou de ganhar. Não vislumbro que a hipótese dos autos exige a recomposição de lucros cessantes, pois a alegação seria de que seria o valor alcançado com a comercialização da mercadoria, se em mãos a tivesse à época da infrutífera remoção.

5 - No que concerne ao valor da saca de açúcar, como já mencionado em uma preliminar apreciação, trata-se de mercadoria com cotação em bolsa, portanto de fácil verificação, todavia, por depender do mercado e - no caso do açúcar - de produção, safras e outras particularidades, tem o preço variável.

6 - Agravo de Instrumento parcialmente provido. [grifos nossos]

Esta oscilação no valor de cotação do bem pode trazer dificuldades para que o magistrado fixe o valor do lance mínimo do leilão, por exemplo (art. 885, CPC). Uma saída pode ser determinar a realização de uma nova avaliação em data mais próxima à realização do leilão (art. 873, II, CPC). De qualquer forma, diante de bens com muita volatilidade de preço há dois cenários possíveis: (i) o valor aumentar e, neste caso, o saldo que sobrar após o pagamento da dívida deve ser devolvido ao executado e (ii) o valor diminuir. O Bitcoin, que no último trimestre de 2017 chegou a valer $\mathrm{R} \$ 70.000,00$ (setenta mil reais) hoje vale $\mathrm{R} \$$ 23.800,00 (vinte e três mil e oitocentos reais) a unidade (MERCADO BITCOIN, 2018). Isso representa uma queda de $66 \%$ em um intervalo de mais ou menos 6 meses.

Uma solução interessante apresentada por Alexandre Antonio Freitas Câmara, desembargador do Tribunal de Justiça do Estado do Rio de Janeiro, ${ }^{15}$ é a aplicação analógica do art. 852, inciso I, do CPC, que permite a alienação antecipada dos bens penhorados quando se tratar de bens sujeitos à depreciação. Esta é exatamente a situação das criptomoedas. Nesta hipótese, há uma flexibilização procedimental prevista em lei a fim de garantir a eficácia da determinação judicial para a satisfação do crédito.

\footnotetext{
${ }^{15}$ CANAL PROF. PRISCILLA MENEZES. Entrevista Des. Alexandre Câmara - Possibilidade de penhora de criptomoedas. Disponível em: 〈https://www.youtube.com/watch?v=2s_0g-8tjjA〉. Acesso em 25.mar. 2018.
} 
Além dessas questões, muito se debateu sobre a possibilidade prática de se encontrar as criptomoedas do devedor. Aqueles, como Marcelo Lauar Leite (2017), que entendem ser ineficaz a penhora de criptomoedas alegam que

o grande debate a ser travado sobre esse tema diz respeito à efetividade de uma ordem de penhora sobre Bitcoins, tamanha a complexidade de seus processos de organização, validação e circulação. Em outras palavras, penhorar criptomoeda é, hoje, um ato jurídico exequível?

Se a prudência recomenda a ressalva do "depende" na formulação de respostas jurídicas em geral, aqui, estamos diante de um caso potencializado. Vivo fosse, Guimarães Rosa talvez o chamasse de grandepende. Por quê?

Diferente do que ocorre com a circulação de moedas e valores mobiliários, as criptomoedas padecem de controle de autoridades financeiras ou do mercado de capitais (como o Banco Central e a CVM). Para penhorar Bitcoins, o magistrado precisaria saber onde eles estão depositados, informação obscura quando inexiste um poder ou intermediador centralizado $[\ldots]$

Ora, é claro que a existência de uma autoridade central, controladora, reguladora ou certificadora como o Banco Central do Brasil, a Comissão de Valores Mobiliários, o DETRAN e ou o Registro Geral de Imóveis, no âmbito de suas atribuições, para a qual o Poder Judiciário possa enviar um ofício determinando o fornecimento das informações solicitadas facilita a busca por bens. Não obstante, existe um sem-número de bens igualmente penhoráveis que carecem de um órgão com tais características. O que dizer da possibilidade de penhora de obras de arte, joias ${ }^{16}$ de elevado valor, vestidos de grife, aparelhos de TV de última geração? A penhora de tais bens já está consolidada na jurisprudência, posto não serem registráveis, como indica o julgado abaixo do Tribunal Regional do Trabalho da Terceira Região (BRASIL. Tribunal Regional do Trabalho. Terceira Região, 2012).

\section{AGRAVO DE PETIÇÃO - ARGUIÇÃO DE IMPENHORABILIDADE DOS BENS CONSTRITOS - ALCANCE E ESCOPO DA LEI N. 8.009/90.}

A impenhorabilidade dos bens que guarnecem a residência do executado, assegurada na Lei 8.009/90, não abrange todo e qualquer móvel, posto que o escopo da lei não é amparar o executado de meios legais para se furtar à responsabilização pelos seus débitos, mas garantir-lhe, e à sua família, o

\footnotetext{
${ }^{16}$ Embora sejam hipoteticamente penhoráveis, decisão da Quinta Câmara Cível do Tribunal de Justiça do Estado de Goiás (TJGO) no Agravo de Instrumento n. 102347-66.2015.8.09.0000 (201591023475), entendeu que um quadro a óleo de Di Cavalcanti, cujo valor é de mais ou menos $\mathrm{R} \$ 500.000,00$ (quinhentos mil reais), não poderia ser penhorado porque era de difícil conversão em dinheiro. No caso concreto, a executada devia $\mathrm{R} \$ 260$ mil e indicou o quadro para penhora com fulcro no art. $829, \S 2^{\circ}$, CPC para evitar que a constrição judicial recaísse sobre um apartamento.
} 
mínimo necessário para uma sobrevivência digna. Na hipótese vertente, não afronta aos ditames legais a constrição judicial que recai sobre aparelhos de televisão e home theater, que, embora se mostrem úteis e tragam comodidade à vida doméstica, ao conforto mediano do devedor e de sua família, não se sobrepõem à necessidade de subsistência do trabalhador, revestidos que são os créditos trabalhistas de ínsita natureza alimentar. Agravo desprovido, ao enfoque. [grifos nossos]

É claro que ao adentrar em um imóvel, seja ele comercial ou residencial, o oficial de justiça enxerga bens materiais como os quadros, aparelhos eletrônicos de elevado valor com mais facilidade; mas, como encontrar criptomoedas?

Há duas possibilidade: (i) armazenamento virtual ou (ii) armazenamento em disco rígido (hardwares). No primeiro caso, havendo notícias, informações de que o executado tem por hábito investir em criptomoedas, deve o Poder Judiciário enviar ofícios para as corretoras de criptomoedas (a lista deve ser fornecida pelo exequente) a fim de obter tais informações. Vale lembrar que, nos dias atuais, muitas informações deste tipo (acerca dos hábitos e atividades das pessoas) estão disponíveis nas redes sociais de forma pública e inseridas pelos próprios devedores no ensejo de demonstrar poder, riqueza ou por ato de vaidade.

No segundo caso, quando houver baixa da internet (download) das criptomoedas e armazenamento em hardwares como HDs externos e pendrives, também é possível a determinação de busca e apreensão dos dispositivos. A modalidade de "penhora portas a dentro" continua válida e útil no processo civil, porém agora estas portas além de físicas são também virtuais ${ }^{17}$.

Ao determinar uma varredura na vida virtual de qualquer pessoa, Alexandre Freitas Câmara ${ }^{18}$ alerta para um cuidado necessário, pois numa busca ampla como esta encontrar-seão elementos não relacionados com a criptomoeda e que estão ligados com a intimidade, a privacidade da parte. A solução para isso seria a decretação do segredo de justiça, seguido de uma autuação apartada. Assim, a documentação dos atos relacionados a estas diligências

\footnotetext{
${ }^{17}$ A penhora "portas a dentro", ou com arrombamento, é disciplinada no art. 846 do CPC, sendo cabível se o executado fechar as portas da casa a fim de obstar a penhora dos bens. Cabe ao oficial de justiça comunicar o fato ao juiz, solicitando-lhe ordem de arrombamento. Deferido o pedido, 2 (dois) oficiais de justiça cumprirão o mandado, arrombando cômodos e móveis em que se presuma estarem os bens, e lavrarão de tudo auto circunstanciado, que será assinado por 2 (duas) testemunhas presentes à diligência. Sempre que necessário, o juiz poderá requisitar força policial, a fim de auxiliar os oficiais de justiça na penhora dos bens. Os oficiais de justiça lavrarão em duplicata o auto da ocorrência, entregando uma via ao escrivão ou ao chefe de secretaria, para ser juntada aos autos, e a outra à autoridade policial a quem couber a apuração criminal dos eventuais delitos de desobediência ou de resistência. Do auto da ocorrência constará o rol de testemunhas, com a respectiva qualificação.

${ }^{18}$ CANAL PROF. PRISCILLA MENEZES. Entrevista Des. Alexandre Câmara - Possibilidade de penhora de criptomoedas. Disponível em: 〈https://www.youtube.com/watch?v=2s_0g-8tjjA〉. Acesso em: 25.mar.2018.
} 
(busca e apreensão de criptomoedas) seria autuada de alguma maneira para que as partes tenham acesso e possa haver o exercício do direito ao contraditório a respeito disso. Obtidos os documentos necessários, identificada a criptomoeda, aquilo que for necessário para que se possa efetivar a penhora deve ser juntado aos autos principais, enquanto o restante da documentação deve ser devolvida para o executado. A partir disso o processo volta a ser público. Esta solução é análoga ao procedimento para quebra de sigilo em execução.

A respeito do cuidado e dos limites quanto a investigação da vida privada do devedor para cumprimento de decisão ou ato judicial, cabe citar a elucidativa ementa de julgado da Segunda Turma do Superior Tribunal de Justiça (BRASIL.Superior Tribunal de Justiça, 2011).

PROCESSUAL CIVIL. VIOLAÇÃO AOS ARTS. 537, 557 E 535 DO CPC. NAO OCORRÊNCIA. EXECUÇÃO FISCAL. RESPOSTA DAS INSTITUIÇÕES FINANCEIRAS AO OFÍCIO DE REQUISIÇÃO DE INFORMAÇÃO DE ATIVOS FINANCEIROS VIA BACEN-JUD. DOCUMENTOS SIGILOSOS. INEXISTÊNCIA DE PREVISÃO LEGAL PARA ARQUIVAMENTO FORA DOS AUTOS. DECRETAÇÃO DE SEGREDO DE JUSTIÇA. ART. 155, I, DO CPC.

1. O presente recurso especial originou-se de agravo de instrumento interposto em face de decisão do juiz singular que determinou o arquivamento, em pasta própria, da resposta ao ofício que requisitou informações via Sistema Bacen-Jud, a respeito da existência de ativos financeiros da empresa devedora.

2. A alegada violação aos arts. 537 e 557 do CPC não mais se justifica, sobretudo porque a pretensão de julgamento colegiado dos embargos de declaração restou, ao final e ao cabo, suprida quando do julgamento do agravo regimental interposto pela recorrente.

3. A despeito da ausência de manifestação expressa do Tribunal de origem sobre os arts. $3^{\circ}$ da Lei Complementar n. 105/2001 e 155, I, do CPC, o acórdão recorrido se manifestou de forma clara e fundamentada quanto à possibilidade de manutenção dos documentos sigilosos em pasta própria na Secretaria da Vara, o que atenderia à finalidade de proteção aos documentos e acesso às partes. Havendo fundamentação suficiente para suster o acórdão, na forma do art. 93, IX, da Constituição Federal, não há que se falar em nulidade por omissão.

4. É cediço que nem todas as informações prestadas pelas instituições financeiras ao Poder Judiciário têm caráter sigiloso. Na hipótese dos autos, verifica-se à fl. 83 e-STJ que somente foi solicitado ao Bacen informações relativas ao endereço dos envolvidos, existência de contas e aplicações financeiras e à informação de saldo até o limite do débito. Os extratos bancários foram expressamente excluídos do pedido de informação. $\mathrm{O}$ art. $17,3^{\circ}$, do Regulamento do Bacenjud somente submeteu a sigilo as informações relativas a extratos bancários. 
5. Não há no Código de Processo Civil nenhuma previsão para que se crie pasta própria fora dos autos para o arquivamento de documentos submetidos a sigilo. Antes, nos casos em que o interesse público justificar, cabe ao magistrado limitar às partes o acesso aos autos passando o feito a tramitar em segredo de justiça, na forma do art. 155, I, do CPC. Precedente: REsp 819.455/RS, Rel. Min. Teori Albino Zavascki, Primeira Turma, Dje de 4.3.2009.

6. Recurso especial provido. [grifos nossos]

Diante de todo o exposto, constata-se que o Código de Processo Civil brasileiro é fundamento legal e normativo suficiente para viabilizar a penhora e expropriação de criptomoedas a fim de satisfazer credores não pagos, preservando o direito à intimidade do executado, mesmo se for necessária uma investigação de sua privada à procura de bens passíveis de excussão. Em dezembro de 2017 houve o primeiro julgamento sobre o tema das criptomoedas no Brasil, cujo decisão merece análise e críticas no próximo capítulo.

\section{EXEQUIBILIDADE DO BITCOIN E A QUESTÃO DO ÔNUS DA PROVA: LEADING CASE DO TRIBUNAL DE JUSTIÇA DO ESTADO DE SÃO PAULO}

Em novembro de 2017, a Trigésima Sexta Câmara de Direito Privado do TJ-SP confirmou a denegação pelo juiz monocrático de um pedido de penhora de bitcoins. $\mathrm{Na}$ espécie, tratava-se de execução por título extrajudicial na qual o exequente Santander Leasing S.A. Arrendamento Mercantil (agravante) indicou as criptomoedas dos executados na forma do art. 798, II, alínea c, c/c art. 829, $\S 2^{\circ}$, ambos do CPC.

Sustentou a agravante a possibilidade de penhora de moeda criptografada, ainda que se trate de bem imaterial, já que possui conteúdo econômico. Afirmou que a ordem deve ser emitida para as administradoras de moeda criptografada e alegou que a ausência de regulamentação sobre o bitcoin não pode justificar o indeferimento da penhora. Conclui a agravante que o pedido está amparado no artigo 139, IV, do Código de Processo Civil. Foi indeferido pelo relator do recurso pedido liminar formulado pela agravente.

No acórdão fixou-se o entendimento de que o Bitcoin é bem imaterial com caráter patrimonial e, portanto, sujeito em tese ao ato de constrição. O relator do recurso ponderou que ausência de regulamentação não tem o condão de inviabilizar a penhora, devendo-se oficiar às administradoras de moedas criptografadas, se for o caso. Entretanto, tanto o Juízo de 
primeiro grau quanto o Tribunal entenderam não ser cabível atender ao pedido do exequente porque este teria sido "genérico" (SÃO PAULO. Tribunal de Justiça, 2017).

Por se tratar de bem imaterial com conteúdo patrimonial, em tese, não há
óbice para que a moeda virtual possa ser penhorada para garantir a execução.
Entretanto, a agravante não apresentou sequer indícios de que os
agravados tenham investimentos em bitcoins ou, de qualquer outra
forma, sejam titulares de bens dessa natureza. Tampouco evidenciado
que os executados utilizam moedas virtuais em suas atividades. Como se
nota, o pedido formulado é genérico e, por essa razão, não era mesmo de
ser acolhido. Competia à agravante comprovar a existência dos bens que
pretende penhorar, uma vez que não se pode admitir o envio
indiscriminado de ofícios sem a presença de indícios mínimos de que os
executados sejam titulares dos bens. [grifos nossos]

Segundo o relator, o ônus da prova da existência dos bens cabe ao exequente/agravante. No caso concreto, este chegou a indicar ao juiz duas corretoras atuantes na intermediação de serviços e negócios pela internet para envio de ofício, a fim de verificar a existência e quantidade de criptomoedas dos executados. Porém, o pedido foi negado diante da ausência de prova ou indícios de que as corretoras, de fato, tinham atuação como agentes de custódia de bitcoins ou de sua relação com possíveis bens dos agravados.

Para os desembargadores, competia à agravante comprovar a existência dos bens que pretende penhorar, uma vez que não se pode admitir o envio indiscriminado de ofícios sem a presença de indícios mínimos de que os executados sejam titulares dos bens.

Em relação à interpretação do inciso IV do art. 139 do CPC, a Câmara argumentou que mesmo sendo atribuição do juiz determinar todas as medidas indutivas, coercitivas, mandamentais ou sub-rogatórias necessárias para assegurar o cumprimento de ordem judicial, cabe ao exequente comprovar a eficácia da medida pretendida e indícios da existência dos bens, o que não ficou demonstrado no caso diante do pedido "genérico" formulado.

A decisão poderia ter analisado o caso por outro espectro e algumas ponderações devem ser postas.

De forma analógica, caso se tratasse de penhora de dinheiro cuja localização é incerta, seria possível afirmar que seria ônus do exequente informar ao juízo em qual banco o executado mantém conta corrente e investimentos? Certamente que não. Cabe apenas ao exequente requerer a penhora de dinheiro ou aplicação financeira, na forma do art. 854 do CPC. O convênio BACEN-JUD permite rastrear todas as instituições financeiras do 
executado apenas pelo CPF ou CNP e tornar indisponíveis ativos financeiros existentes em nome dele.

O fato de não haver uma entidade central de corretoras de criptomoedas ou de casas de câmbio é o suficiente para transferir esse ônus para o exequente? Acredita-se que não. Segundo o art. 139, inciso IV, incumbe ao juiz determinar todas as medidas indutivas, coercitivas, mandamentais ou sub-rogatórias para assegurar o cumprimento de ordem judicial, inclusive nas ações que tenham por objeto prestação pecuniária.

Não se pode impor ao exequente um ônus do qual ele não possa se desimcumbir. Imagine-se o credor solicitando tais informações à casas de câmbio ou ao próprio exequente. Provavelmente não será atendido sob justificativa de sigilo das operações. Porém, ordens emanadas do Poder Judiciário são obedecidas, sob pena de consequências severas.

Por exemplo, o juiz pode determinar que o executado pague a dívida ou indique bens à penhora na forma do art. $829, \S 2^{\circ}$, do CPC. O princípio da cooperação entre as partes foi positivado no art. $6^{\circ}$ do CPC e seu descumprimento pode vir a ser considerado ato atentatório à dignidade da justiça.

Art. 77. Além de outros previstos neste Código, são deveres das partes, de seus procuradores e de todos aqueles que de qualquer forma participem do processo:

[...]

IV - cumprir com exatidão as decisões jurisdicionais, de natureza provisória ou final, e não criar embaraços à sua efetivação;

$[\ldots]$

$\S 1^{\circ}$ Nas hipóteses dos incisos IV e VI, o juiz advertirá qualquer das pessoas mencionadas no caput de que sua conduta poderá ser punida como ato atentatório à dignidade da justiça.

$\S 2^{\circ} \mathrm{A}$ violação ao disposto nos incisos IV e VI constitui ato atentatório à dignidade da justiça, devendo o juiz, sem prejuízo das sanções criminais, civis e processuais cabíveis, aplicar ao responsável multa de até vinte por cento do valor da causa, de acordo com a gravidade da conduta.

$\S 3^{\circ}$ Não sendo paga no prazo a ser fixado pelo juiz, a multa prevista no $\S 2^{\circ}$ será inscrita como dívida ativa da União ou do Estado após o trânsito em julgado da decisão que a fixou, e sua execução observará o procedimento da execução fiscal, revertendo-se aos fundos previstos no art. 97. [...] (grifos nossos)

O trabalho de identificação dos bens do devedor no que se refere à busca por criptomoedas só pode ter êxito com o auxílio efetivo do Poder Judiciário. Na visão de 
Alexandre Freitas Câmara, ${ }^{19}$ com a qual se coaduna o presente trabalho, mostra-se desarrazoado e desproporcional impor prova diabólica ao exequente. Se houve solicitação, no caso concreto, de medida específica a fim de localizar criptomoedas dos executados, o pleito deveria ter sido atendido.

\section{CONCLUSÃO}

Cada vez mais as transformações sociais ocorrem em intervalos menores e a adaptação tem que ser tão rápida a ponto de acompanha-las. Tanto modelos de negócio quanto relações interpessoais e de trabalho mudam, mas para o Direito é impossível acompanhar tantas alterações. Sendo assim, na medida do possível, é necessário fazer um exercício hermenêutico, recorrer ao método de integração analógico e à interpretação sistemática, a fim de fazer cumprir a mens legis.

O presente trabalho se propôs a analisar a viabilidade legal e procedimental da penhora de criptomoedas à luz do atual Código de Processo Civil. Por todos os argumentos aqui expostos defende-se que as criptomoedas, por serem bens imateriais dotados de conteúdo econômico e não estarem inseridas nas exceções legais de impenhorabilidade, são sim passíveis de atos de constrição judicial (penhora, arrolamento, arrecadação, arresto, entre outros), pois estão sujeitas ao princípio da responsabilidade patrimonial do devedor.

$\mathrm{O}$ fato de tais moedas serem transacionadas em um ambiente criptografado e descentralizado (Blockchain) por si só não inviabiliza sua identificação e penhora, pois muitos dos bens sujeitos à esta medida (v.g. joias, obras de arte, etc) também não contam com uma entidade certificadora, controladora ou registradora, como os bens que guarnecem um imóvel residencial ou comercial, por exemplo.

Já a questão da elevada volatilidade de valor também pode ser contornada com a aplicação analógica dos bens sujeitos à depreciação, solução esta presente no processo civil brasileiro há muitos anos.

Sendo assim, percebe-se que apesar da grande novidade que essas moedas representam, é possível determinar medidas tradicionais do Código de Processo Civil, como a penhora "portas a dentro" em busca de hardwares, quebras de sigilo digital (varredura de emails, carteiras virtuais) e expedição de ofícios em busca desses bens para a satisfação do

\footnotetext{
${ }^{19}$ CANAL PROF. PRISCILLA MENEZES. Entrevista com o Des. Alexandre Freitas Câmara - Possibilidade de penhora de criptomoedas. Disponível em: 〈https://www.youtube.com/watch?v=2s_0g-8tjjA>. Acesso em 25 mar. 2018.
} 
credores. O que não se deve admitir, é a transferência desse ônus para o exequente que não tem como se desimcumbir dele.

\section{REFERÊNCIAS}

BRASIL. BANCO CENTRAL DO BRASIL. Museu de Valores do Banco Central. Disponível em: <https://www.bcb.gov.br/htms/origevol.asp>. Acesso em 19 mar. 2018.

Lei n. 7.357 de 2 de setembro de 1985. Dispõe sobre o cheque e dá outras providências. Disponível em: <http://www.planalto.gov.br/ccivil_03/leis/17357.htm>. Acesso em 03 abr. 2018.

Lei n. 13.105 de 16 de março de 2015. Código de Processo Civil. Disponível em: <http://www.planalto.gov.br/ccivil_03/_ato2015-2018/2015/lei/113105.htm>. Acesso em 05 abr. 2018.

Superior Tribunal de Justiça. Segunda Turma. Recurso Especial 1.245.744 / SP. Relator: Ministro Mauro Campbell Marques. Data do julgamento: 28/06/2011. Disponível em: <https://stj.jusbrasil.com.br/jurisprudencia/21102987/recurso-especial-resp-1245744-sp2011-0040157-0-stj/inteiro-teor-21102988?ref=juris-tabs>. Acesso em 04 abr. 2018.

. Tribunal Regional Federal. Terceira Região. Terceira Turma. Agravo de Instrumento 2007.03.00.040518-1. Relator: Des. Nery Junior. Data do julgamento: 05/09/2007. Disponível em: <https://trf-3.jusbrasil.com.br/jurisprudencia/18851471/agravo-deinstrumento-ag-40518-sp-20070300040518-1-trf3>. Acesso em 03 abr. 2018.

. Tribunal Regional do Trabalho. Terceira Região. Agravo de petição 01558-2011022-03-00-4. Relator: Julio Bernardo do Carmo. Data do julgamento: 02/05/2012. Disponível

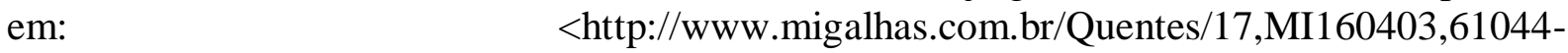
Televisao+LCD+e+home+theater+sao+penhoraveis>. Acesso em 29 mar. 2018.

CANAL PROF. PRISCILLA MENEZES. Entrevista Des. Alexandre Câmara - Possibilidade de penhora de criptomoedas. Disponível em: <https://www.youtube.com/watch?v=2s_0g8tjjA>. Acesso em 25 mar. 2018.

CASTRO, Moema Augusta Soares de. Cartão de Crédito: a monética, o cartão de crédito e o documento eletrônico. Rio de Janeiro: Forense, 1999.

COIN NEWS TELEGRAPH. Preço do Bitcoin: Quão baixo a criptomoeda cairá à medida que a incerteza da "bolha"surgir? Disponível em: <https://coinnewstelegraph.com/pt/bitcoinprice-how-low-will-cryptocurrency-fall-as-bubble-uncertainty-emerges/>. Acesso em 24 mar. 2018.

GOIÁS. Tribunal de Justiça. Quinta Câmara Cível. Agravo de instrumento n. 10234766.2015.8.09.0000 (201591023475). Relator: Des. Delintro Belo de Almeida Filho. Data do julgamento: 16/04/2015. Disponível em: <http://www.tjgo.jus.br/images/docs/ccs/delintro_obradearte.PDF>. Acesso em 03 abr. 2018. 
GUIA MUNDO. BITCOIN: O futuro do dinheiro. 2. ed. São Paulo: Online, 2017.

FORTUNE. Why Sweden is going cash-free? Disponível em: <http://fortune.com/2015/12/26/sweden-cash-free/>. Acesso em 13 mar. 2018.

LEITE, Marcelo Lauar. Penhora de bitcoins é possível, mas de difícil realização. Disponível em: <https://www.conjur.com.br/2017-dez-07/marcelo-lauar-execucao-penhora-bitcoinsimprovavel>. Acesso em 02 abr. 2018.

MARKET PLACE. Sweden is moving away from cash, and some businesses will no longer accept it. Disponível em: <https://www.marketplace.org/2017/07/17/economy/swedenmoving-away-from-cash-some-businesses-will-no-longer-accept-it>. Acesso em 13 mar. 2018.

MARTINS, Fran. Cartões de crédito: natureza jurídica. Rio de Janeiro: Forense, 1976.

MERCADO BITCOIN. Disponível em: <https://www.mercadobitcoin.com.br/>. Acesso em 07 abr. 2018.

NAKAMOTO, Satoshi. Bitcoin: A peer to peer eletronic cash-system. Disponível em: <https://bitcoin.org/bitcoin.pdf>. [s/d]. Acesso em 16 mar. 2018.

OLIVEIRA, Celso Marcelo de. Cartão de crédito: de acordo com o Novo Código Civil. Campinas: LNZ Editora, 2003.

TAPSCOTT, Don; TAPSCOTT, Alex. Blockchain Revolution: como a tecnologia por trás do Bitcoin está mudando o dinheiro, os negócios e o mundo. Tradução colaborativa. São Paulo: SENAI-SP Editora, 2016.

SÃO PAULO. Tribunal de Justiça. Trigésima Sexta Câmara de Direito Privado. Agravo de Instrumento $\mathrm{n}^{\mathrm{o}}$ 2202157-35.2017.8.26.0000. Relator: Des. Milton Carvalho. Data do julgamento: 21/11/2017. Disponível em: <https://www.conjur.com.br/dl/bitcoin-penhoradaquem-provar-devedor.pdf>. Acesso em 02 abr. 2018.

SCHWAB, Klaus. A quarta revolução industrial. Tradução de Daniel Moreira Miranda. São Paulo: Edipro, 2016. 